\title{
Pengaruh Penyuluhan Terhadap Pengetahuan Sikap Perilaku Kader PKK Kelurahan Sukagalih Kota Bandung Tentang Diabetes Mellitus
}

\author{
Audyati Gany, Kartika Suhada, Cindra Paskaria, Meilinah Hidayat \\ Universitas Kristen Maranatha \\ Email: audy.gany@gmail.com, tikas56@gmail.com,cpaskaria@yahoo.com, \\ mellahidayat@yahoo.com
}

\begin{abstract}
:
Diabetes Mellitus is a chronic metabolic disorder which is a serious problem for the health of the people of Indonesia and the world, so the International Diabetes Federation (IDF) and the World Health Organization (WHO) set November 14 as World Diabetes Day. The aim of the research is to increase public knowledge about Diabetes Mellitus, to behave and behave as they should in their daily lives, starting with lifestyle and patterns of food and drink intake. Counseling is carried out to PKK cadres as the spearhead who continue to the community members. The study design was a lecture accompanied by cross sectional pre and post test data collection. The results of the knowledge aspects of the study showed that there was a very significant difference between the pre and post test results $(p=0,000)$. The attitude aspect showed that there was no significant difference between the pre and post test results ( $p=0.257)$, but overall the cadre's attitude regarding a healthy lifestyle to prevent Diabetes Mellitus was good enough. Behavioral aspects indicate that there are respondents who behave well, a maximum value of 3 , but some are not good, a minimum value of 0 . The results of blood sugar tests when showing as many as $69.57 \%$ of participants are not certain to have DM, while the rest are not DM. The conclusion is that there is a very significant increase in PKK cadre knowledge, but there has not been a significant change in attitude after attending counseling.
\end{abstract}

Keyword: Diabetes Mellitus, Knowledge, Attitude, Behavior, Cadre

\section{Pendahuluan}

Faktor penting yang harus menjadi perhatian manusia dalam menunjang kelancaran aktivitas sehari-hari adalah kesehatan tubuh. Upaya manusia dalam hal menjaga kesehatan tubuh mendapat perhatian dari berbagai pihak, salah satunya adalah International Diabetes Federation (IDF) dan World Health Organization 
(WHO) yang kemudian mencetuskan ide Hari Diabetes Sedunia (World Diabetes Day, WDD) yang jatuh pada setiap tanggal 14 November dan sudah diperingati sejak tahun 1991. Penyakit Diabetes Mellitus (DM) atau Diabetes merupakan penyakit gangguan metabolik menahun akibat pankreas tidak dapat memproduksi cukup insulin atau tubuh tidak dapat menggunakan insulin yang diproduksi secara efektif, yang berakibat terjadi peningkatan konsentrasi glukosa di dalam darah (hiperglikemia). Insulin itu sendiri adalah hormon yang mengatur keseimbangan kadar gula darah. Penyakit diabetes merupakan penyakit yang erat hubungannya dengan asupan makanan. Pola kebiasaan makan, dan gaya hidup yang keliru mengakibatkan terjadinya peningkatan gula darah, dan apabila hal ini berlangsung dalam waktu yang lama dapat menyebabkan penyakit Diabetes (Susanti, 2018). Seseorang yang telah didiagnosis DM tipe-2 harus dapat menjaga kadar gula darah tetap di rentang normal agar tidak berlanjut pada komplikasi. Komplikasi yang mungkin timbul akibat penyakit diabetes adalah penyakit ginjal, kulit, saraf (neuropati), mata, gangguan jantung dan pembuluh darah (Papatheodorou, 2016). Dengan pengobatan yang benar, perubahan pola kebiasaan makan dan gaya hidup yang lebih baik, komplikasi diabetes dapat dicegah (ADA, 2018).

Tahun 2014 menandai tahun pertama dari tiga tahun (2014 - 2016) yang berfokus pada tema "Healthy Living and Diabetes" dengan slogan "Diabetes Protect Our Future" dengan pesan kunci "Make healthy food the easy choice, Healthy eating : make the right choice, Healthy eating begins with breakfast". Estimasi IDF pada tahun 2013, di dunia terdapat 382 juta orang yang hidup dengan diabetes, dan pada tahun 2035 diperkirakan akan meningkat menjadi 592 juta orang. Dengan perkiraan dari 382 juta orang tersebut, terdapat 175 juta diantaranya belum terdiagnosis, sehingga terancam berkembang secara progresif menjadi komplikasi yang tanpa disadari dan tanpa pencegahan (InfoDATIN, 2014). Penyakit Diabetes merupakan penyakit degeneratif yang dapat dikendalikan dengan memperhatikan pola makan dan asupan yang seimbang, karenanya diet yang tepat menjadi salah satu cara pencegahan penyakit diabetes (Soegondo, 2015). 
Desain penelitian yang dilakukan adalah dengan melakukan ceramah yang disertai dengan pengambilan data pre dan post test secara cross sectional. Cross sectional merupakan suatu studi epidemiologi yang mempelajari prevalensi, distribusi, serta bagaimana menghubungkannya dengan penyakit yang menjadi paparan dalam penelitian ini, dengan melakukan pengamatan pada individuindividu dari suatu populasi pada suatu saat

Penyuluhan adalah suatu bentuk promosi dengan cara penyampaian informasi, sehingga aktivitas penyuluhan kesehatan adalah suatu bentuk promosi kesehatan dengan memberikan informasi atau pesan kesehatan, sehingga dapat mengintervensi faktor perilaku dalam masalah kesehatan masyarakat. Perilaku kesehatan masyarakat mencakup tiga domain, yaitu; pengetahuan (knowledge), sikap (atitude), dan tindakan (practice). Pengetahuan kesehatan adalah mencakup apa yang diketahui oleh seseorang terhadap cara-cara pemeliharaan kesehatan. Sikap terhadap kesehatan adalah pendapat atau penilaian orang terhadap hal-hal yang berkaitan dengan pemeliharaan kesehatan. Tindakan untuk hidup sehat adalah semua kegiatan seseorang dalam rangka memelihara kesehatannya. Penyuluhan yang dilakukan terhadap kader Pembinaan Kesejahteraan Keluarga (PKK) kelurahan Sukagalih bertujuan untuk memberi pengetahuan mengenai Diabetes Mellitus, sehingga diharapkan sikap dan perilaku kader dapat berubah menjadi lebih baik dalam upaya pencegahan penyakit Diabetes Mellitus.

Kader adalah orang atau sekumpulan orang yang dibina oleh suatu lembaga kepengurusan dalam sebuah organisasi, baik sipil maupun militer, yang berfungsi sebagai 'pemihak' dan atau membantu tugas dan fungsi pokok organisasi tersebut. Dalam hal membantu tugas dan fungsi pokok organisasi tersebut, seorang kader dapat berasal dari luar organisasi tersebut dan biasanya merupakan simpatisan yang berasas dan bertujuan sama dengan institusi organisasi yang membinanya. Dengan demikian dalam hal ini, kader merupakan ujung tombak sebagai penggerak masyarakat untuk berperilaku hidup sehat, yang kemudian akan menyebarkan informasi yang diperoleh kader saat penyuluhan kepada masyarakat di wilayahnya 
90 | Pengaruh Penyuluhan Terhadap Pengetahuan Sikap Perilaku Kader PKK ...

masing-masing.

Kader Pembinaan Kesejahteraan Keluarga (PKK) bertugas untuk menjalankan 10 Program Pokok PKK, yang salah satunya adalah program Kesehatan (program ke-7). Kesehatan adalah kebutuhan dasar manusia, sehingga orang harus belajar bagaimana cara menjaga dan memelihara kesehatan diri, keluarga dan lingkungannya. Memelihara kesehatan diri sendiri, keluarga dan lingkungannya sangat erat kaitannya dengan persoalan kemiskinan dan ketidaktahuan, serta pendidikan yang rendah. Setiap orang mempunyai tugas kewajiban dan bertanggung-jawab untuk memelihara kesehatan diri sendiri, keluarga dan lingkungannya. Orang harus tahu dan mewujudkannya dalam sikap hidup seharihari untuk hidup bersih dan sehat, serta menjaga lingkungan yang sehat, baik di dalam maupun di luar rumah.

Kader PKK di Kelurahan Sukagalih, Kecamatan Sukajadi Bandung terbagi dalam 4 Kelompok Kerja (disingkat Pokja). Pokja ke 4 bertugas sebagai pengelola program kesehatan, kelestarian lingkungan hidup dan perencanaan sehat. Untuk itulah wawasan para kader tentang kesehatan perlu terus diupayakan agar mengalami peningkatan. Salah satu upaya peningkatan wawasan yang dapat dilakukan adalah melalui penyuluhan, yang salah satunya adalah penyuluhan mengenai Diabetes Mellitus (DM).

Sebagai bentuk kepedulian, Ikatan Kekeluargaan Perempuan Maranatha (IKPM) memberikan penyuluhan tentang bahaya penyakit diabetes yang disertai dengan pemeriksaaan gula darah sewaktu secara gratis kepada para Kader PKK di Kelurahan Sukagalih. Dengan penyuluhan yang diberikan diharapkan Pengetahuan, Sikap dan Perilaku para kader tersebut meningkat, yang nantinya dapat meningkatkan pula Pengetahuan, Sikap dan Perilaku masyarakat Indonesia secara umum.

Hasil akhir dari kegiatan penyuluhan ini, diharapkan terjadi peningkatan pemahaman para Kader PKK tentang bahaya penyakit diabetes, yang kemudian diikuti dengan adanya perubahan sikap dan perilaku dalam hal pola makan/minum 
dan gaya hidup, sehingga kesehatan mereka pun meningkat dan mereka dapat mengetahui kondisi kesehatannya terkait dengan gula darahnya. Dengan peningkatan yang terjadi, diharapkan mereka dapat bertindak sebagai penyambung informasi dengan melakukan sosialisasi kepada warga sekitar, sehingga kesehatan warga dapat meningkat pula.

Dari berbagai penelitian epideminologis di Indonesia, pada tahun 1980-an prevalensi Diabetes Mellitus pada penduduk berusia 15 tahun ke atas adalah prevalensi dengan 1,5-2,3\% terjadi di daerah rural / pedesaan lebih rendah bila dibandingkan dengan perkotaan. Dari Survei Kesehatan Rumah tangga (SKRT) 2001, didapat prevalensi Diabetes Mellitus pada penduduk usia 25 - 64 di Jawa dan Bali sebesar 7,5\%.

Terminologi penderita Diabetes Mellitus menurut Riset Kesehatan Dasar (Rikerdas) adalah jika seseorang pernah didiagnosis dokter menderita kencing manis, atau belum pernah didiagnosis menderita kencing manis, namun dalam 1 bulan terakhir mengalami gejala sering lapar, sering haus, sering buang air kecil dengan jumlah banyak dan berat badan turun.

Menurut Riskesdas tahun 2013 ternyata bahwa terjadi peningkatan proporsi Diabetes Mellitus yang hampir dua kali lipat bila dibandingkan dengan riskesdas pada tahun 2007. Meningkatnya proporsi Diabetes Mellitus ini, dapat terjadi karena kurangnya pemahaman pengetahuan tentang penyakit, bahaya dan penyebab dari Diabetes Mellitus, serta batasan kadar gula darah yang normal, sehingga pola hidup dan makan/minum yang baik itu tidak disikapi secara benar serta kurangnya membiasakan diri untuk berperilaku hidup secara baik.

\section{Metode}

Metode yang digunakan dalam kegiatan ini adalah ceramah (gambar 1.) yang dilanjutkan dengan sesi tanya jawab. Kegiatan penyuluhan ini diawali dengan pemeriksaan gula darah sewaktu dari setiap peserta yang hadir (gambar 2.), kemudian peserta diberi pre test (sebelum ceramah dan tanya jawab) dan pada saat 
92 | Pengaruh Penyuluhan Terhadap Pengetahuan Sikap Perilaku Kader PKK ...

selesai ceramah dan sesi tanya jawab, peserta kembali diberi post tes (gambar 3.). Tujuan dari pemberian pre dan post test kepada seluruh kader PKK kecamatan Sukagalih yang mengikuti penyuluhan ini dengan jumlah 23 orang adalah untuk mengetahui apakah ada peningkatan Pengetahuan dan Sikap dari para peserta.

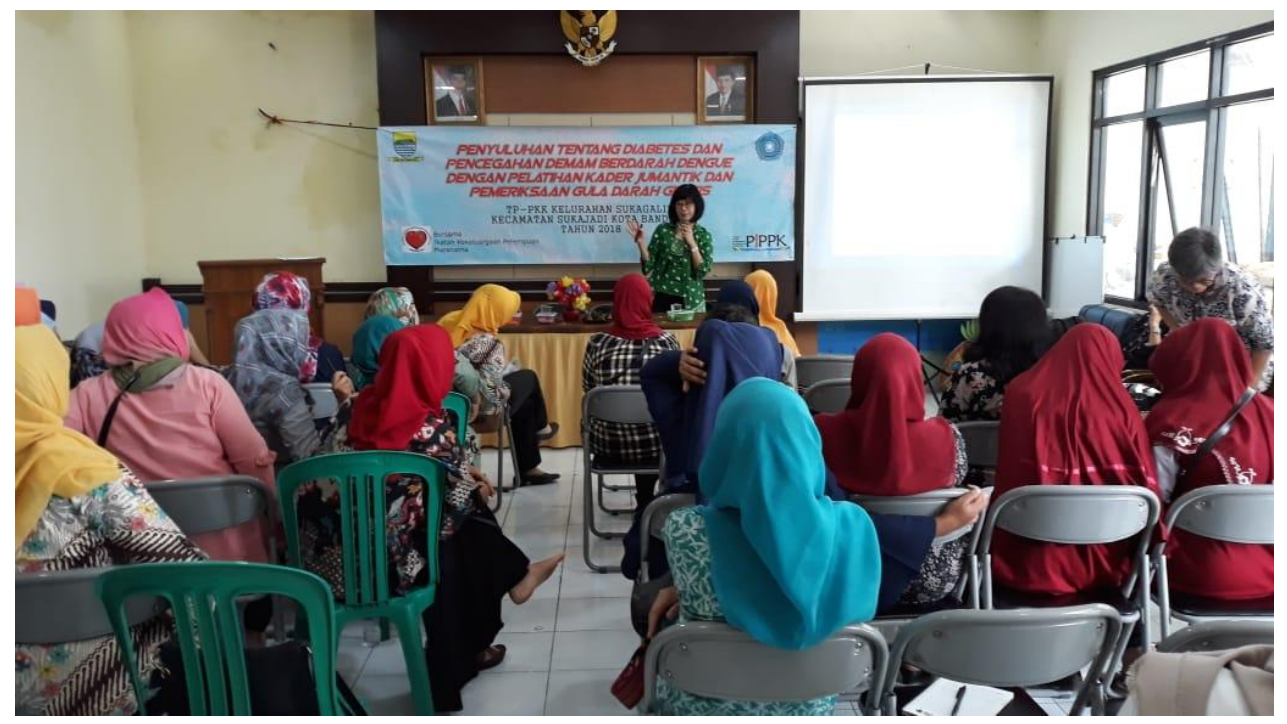

Gambar 1. Ceramah tentang Diabetes Mellitus

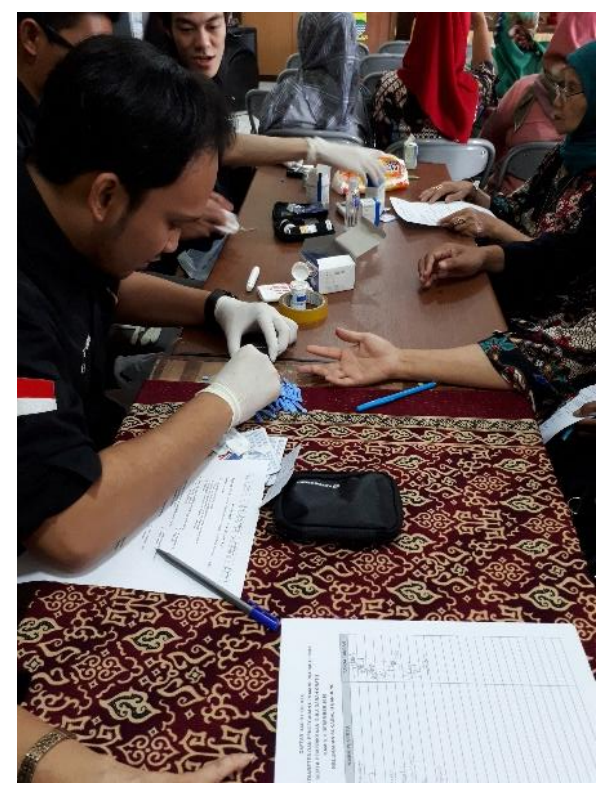

Gambar 2. Pemeriksaan gula darah sewaktu 
Audyati Gany, Kartika Suhada, Cindra Paskaria, Meilinah Hidayat | 93

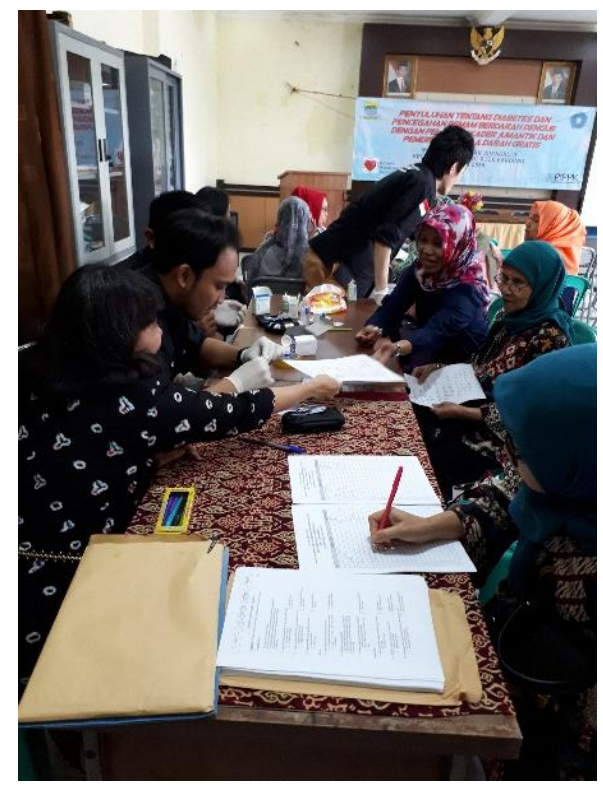

\section{Gambar 3. Peserta mengisi pre test}

Data yang diperoleh dari kuesioner, dianalisis menggunakan uji korelasi Spearman (alpha $=0,05)$ dengan menggunakan bantuan perangkat lunak komputer.

\section{Hasil dan Pembahasan}

Pemeriksaan gula darah sewaktu:

Seluruh peserta penyuluhan melakukan pemeriksaan kadar glukosa darah sewaktu seperti terlihat pada gambar 2, dengan menggunakan alat glukotest. Darah yang diperiksa adalah darah kapiler yang diambil dari ujung jari ketiga atau keempat tangan. Hasil pemeriksaan kadar glukosa darah sewaktu dapat dilihat pada tabel 1.

Tabel 1 Hasil pemeriksaan gula darah sewaktu

\begin{tabular}{|c|l|c|c|}
\hline $\begin{array}{c}\text { Kadar glukosa darah } \\
\text { sewaktu (mg/dL) }\end{array}$ & \multicolumn{1}{|c|}{ Keterangan } & Jumlah & Persentase \\
\hline$<90$ & Bukan DM & 7 orang & $30,43 \%$ \\
\hline $90-199$ & Belum pasti DM & 16 orang & $69,57 \%$ \\
\hline$\geq 200$ & DM & 0 orang & 0 \\
\hline
\end{tabular}


94 | Pengaruh Penyuluhan Terhadap Pengetahuan Sikap Perilaku Kader PKK ...

Sebagian besar peserta penyuluhan memiliki kadar glukosa darah sewaktu 90 - 199 $\mathrm{mg} / \mathrm{dL}(69,57 \%)$, yang berarti peserta penyuluhan belum tentu mengidap DM, namun peserta tersebut disarankan untuk tetap melakukan pemeriksaan ulangan secara rutin.

\section{Aspek Pengetahuan}

Aspek penilaian pengetahuan adalah penilaian sejauh mana responden mengetahui tentang Diabetes Mellitus. Pertanyaan pada pre test dan post test yang berkaitan dengan aspek pengetahuan, yaitu pertanyaan tentang definisi kadar gula darah pemeriksaan sewaktu yang normal, bahaya yang ditimbulkan oleh penyakit diabetes serta penyebab timbulnya penyakit diabetes ini. Hasil dari pre dan post test dapat dikelompokkan ke dalam tabel 2 di bawah ini:

Tabel 2 Perbandingan Pengetahuan kader sebelum dan sesudah penyuluhan

\begin{tabular}{|cccccc|}
\hline Pengetahuan & n & Nilai minimum & $\begin{array}{c}\text { Nilai } \\
\text { maksimum }\end{array}$ & Median & p value \\
\hline Pre test & 23 & 0 & 4 & 3 & \multirow{2}{*}{$0,000^{* * *}$} \\
\hline Post test & 23 & 1 & 4 & 4 \\
\hline
\end{tabular}

Berdasarkan tabel 2 terlihat bahwa terdapat peningkatan pengetahuan kader yang sangat signifikan sebelum dan sesudah penyuluhan mengenai Diabetes Mellitus. Hasil pre test dari 23 responden, menunjukkan nilai minimum pengetahuan terhadap Diabetes Mellitus adalah 0, nilai median adalah 3, dan pada hasil post test terdapat peningkatan, yaitu nilai minimum pengetahuan adalah 1 dan nilai median adalah 4 , sehingga nilai $\mathrm{p}$ menunjukkan perbedaan yang sangat signifikan antara pre dan post test. Salah satu faktor predisposisi perubahan perilaku pada seseorang adalah pengetahuan orang tersebut terhadap apa yang akan dilakukannya. Melalui penyuluhan, terjadi peningkatan pengetahuan kader mengenai penyakit Diabetes Mellitus, faktor penyebab dan bahaya yang 
ditimbulkan akibat penyakit ini, sehingga diharapkan kader dapat lebih termotivasi untuk berperilaku yang baik dalam menjaga pola hidupnya agar tidak terkena penyakit Diabetes Mellitus. (Notoatmojo, 2010)

\section{Aspek Sikap}

Aspek penilaian sikap adalah penilaian sikap responden tentang Diabetes Mellitus. Pre test dan post test aspek sikap meliputi pertanyaan tentang hal-hal yang harus dihindari agar tubuh sehat, apa yang harus dilakukan agar tubuh sehat serta kebiasaan makan dan minum yang disukai oleh responden. Hasilnya dikelompokkan ke dalam tabel 3 di bawah ini:

Tabel 3 Perbandingan Sikap Kader Sebelum dan Sesudah Penyuluhan

\begin{tabular}{|cccccc|}
\hline Sikap & n & Nilai minimum & Nilai maksimum & Median & p value \\
\cline { 1 - 5 } Pre test & 23 & 1 & 3 & 3 & \multirow{2}{*}{$0,257^{\mathrm{ns}}$} \\
\cline { 1 - 5 } Post test & 23 & 1 & 3 & 3 & \\
\hline
\end{tabular}

Berdasarkan tabel 3 dapat terlihat bahwa nilai $\mathrm{p}$ adalah 0,257 yang berarti tidak terdapat perbedaan yang signifikan antara pre dengan post test, dengan perkataan lain tidak terdapat perubahan sikap kader sebelum dan sesudah penyuluhan mengenai Diabetes Mellitus, tetapi secara keseluruhan dapat terlihat bahwa sikap kader mengenai pola hidup yang sehat untuk mencegah terjadinya Diabetes Mellitus sudah cukup baik. Perubahan pengetahuan kader setelah penyuluhan belum diikuti oleh perubahan sikap kader, karena sikap dipengaruhi oleh beberapa faktor. Sikap merupakan kesiapan atau kesediaan untuk bertindak yang terdiri dari 3 komponen pokok, yaitu: (1) kepercayaan atau keyakinan terhadap objek, (2) bagaimana penilaian orang tersebut terhadap objek dan (3) kecenderungan untuk bertindak. Ketiga komponen ini yang secara bersama-sama akan membentuk sikap yang utuh. (Notoatmojo, 2010) 
96 | Pengaruh Penyuluhan Terhadap Pengetahuan Sikap Perilaku Kader PKK ...

Aspek Perilaku

Aspek penilaian Perilaku adalah penilaian perilaku responden tentang Diabetes Mellitus. Pre dan post test aspek perilaku meliputi pertanyaan tentang makanan selingan yang biasa dikonsumsi oleh responden, kebiasaan memasak serta jenis sayuran dan buah-buahan yang biasa dikonsumsi oleh para responden. Hasilnya dikelompokkan ke dalam tabel 4 di bawah ini:

Tabel 4 Gambaran Perilaku Kader

\begin{tabular}{|l|c|c|c|c|}
\hline \multicolumn{1}{|c|}{ Perilaku } & $\mathbf{n}$ & Nilai minimum & Nilai maksimum & Median \\
\hline Pre test & 23 & 0 & 3 & 2 \\
\hline
\end{tabular}

Berdasarkan tabel 4 dapat terlihat bahwa ada kader yang berperilaku baik, ditunjukkan dengan nilai pre test maksimum 3, tetapi ada juga yang kurang baik dalam menjaga pola hidupnya, nilai pre test minimum 0 . Menurut teori Lawrence Green, perilaku ditentukan oleh 3 faktor utama : (1) faktor predisposisi, yaitu faktor yang mempermudah terjadinya perilaku seseorang antara lain pengetahuan, sikap, nilai, dan tradisi, (2) faktor pemungkin, yaitu faktor yang memfasilitasi perilaku seperti sarana dan prasarana, dan (3) faktor penguat, yaitu faktor yang mendorong terjadinya perilaku seperti dukungan dari tokoh masyarakat. Pengetahuan dan sikap kader terhadap Diabetes Mellitus sudah cukup baik, sehingga diharapkan dapat menjadi faktor predisposisi dalam perubahan perilaku kader. Seperti yang diketahui, bahwa masyarakat Indonesia masih menganut pola paternalistik yang masih mengacu kepada perilaku pemimpin baik formal maupun informal, oleh sebab itu kegiatan penyuluhan ini bermanfaat agar kader mampu menjadi model perilaku sehat serta dapat membagikan pengetahuan yang mereka peroleh mengenai Diabetes Mellitus kepada masyarakat sekitar. (Notoatmojo, 2010) 
Audyati Gany, Kartika Suhada, Cindra Paskaria, Meilinah Hidayat | 97

\section{Kesimpulan}

Tingkat pengetahuan Kader PKK kelurahan Sukagalih tentang Diabetes Mellitus mengalami peningkatan yang sangat signifikan setelah mengikuti penyuluhan, sedangkan sikap kader PKK belum mengalami perubahan dan untuk perilaku kader belum dapat dinilai perubahannya. 
98 | Pengaruh Penyuluhan Terhadap Pengetahuan Sikap Perilaku Kader PKK ...

\section{Daftar Pustaka}

American Diabetes Association. ADA. Living with diabetes. [Cited February, 8, 2019]; available from: $\quad$ www.diabetes.org/living-withdiabetes/complications

InfoDATIN, Pusat Data dan Informasi Kementerian Kesehatan RI. Situasi dan Analisis Diabetes. 2014

Notoatmojo, S. 2010. Konsep dan Penerapan Metodologi Penelitian Ilmu Keperawatan. Jakarta: Salemba Medika.

Papatheodorou, K., Papanas, N., Banach, M., Papazoglou, D. \& Edmonds, M. Complications of Diabetes 2016. Journal of Diabetes Research. 2016; 2016:6989453

Soegondo. 2015. Penatalaksanaan Diabetes Mellitusd Terpadu. Jakarta: Balai Penerbit FKUI.

Susanti. 2018. Hubungan Pola Makan dengan Kadar Gula Darah pada Penderita Diabetes Mellitus. Jurnal Kesehatan Vokasional. JkesV. Vol 3 no 1. Mei 2018. ISSN 2599-3275

Tim Penggerak KK Kabupaten Bantul. 10 Program Pokok PKK. [disitasi Febuari, 6, 2019]; pkk.bantulkab.go.id/10-program-pokok-pkk/

Wikipedia. Kader. [disitasi Febuari, 6, 2019]; https://id.wikipedia.org/wiki/kader 